\title{
NOTES ON WIPING CONTACT METHODS FOR CURRENT AND POTENTIAL MEASUREMENTS.
}

BY PROF. BENJ. F. THOMAS.

In the discussion on Mr. Milton E. Thompson's paper on "A Study of an Open Coil Are Dynamo," read before the Institute on the 21st of May, 1891, Dr. Geyer referred to some work done at Stevens Institute by the writer, in which work the wiping contact method seems to have been used for the first time. The following brief account of the work is presented at the request of several members of the Institute.

In the latter part of July, 1880, President Morton requested the writer to determine the power required to maintain the are of a Brush arc light, supplied with current by a Brush dynamo machine.

Ammeters and voltmeters were then unknown, and among the electrical instruments in the Stevens laboratory the most convenient for the purpose seemed to be a tangent galvanometer for the current measurement, and a condenser and Thomson galvanometer for potential. The condenser was a one-third microfard standard, and the galvanometer 7,000 ohm, four-coil astatic, both made by Elliott Bros. As every one now knows would be the case, trouble was encountered the moment the potential readings began. The condenser being first connected to the two carbons, and then discharged through the galvanometer, the successive throws of the needle were found to vary widely, and what seemed at the time most curious, the throws were sometimes to right, and sometimes to left. A little reflection showed that while varying throws in one direction might be due to varying resistance of the 
arc, throws in opposite direction could only be produced by an actual reversal of the potentials of the two carbons. This, of course, led to the conclusion that the potential difference at the terminals of the dynamo must vary with the angular position of the armature as it revolved. Wishing to know the character and magnitude of the variation, the writer devised what is now known as the wiping contact method, the natural and only expedient for the purpose.

The condenser was joined, through the usual discharge key, to

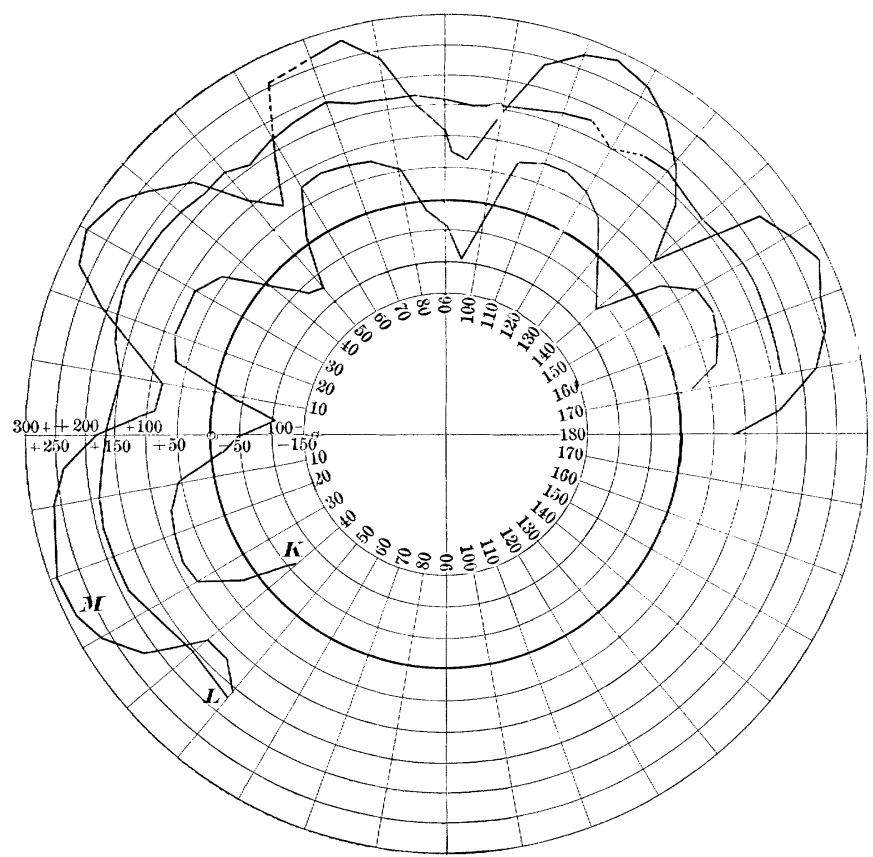

Fig. 1 .

the terminals (or other points) of the dynamo, by two insulated wires. At the dynamo one of these wires was cut, and the cut ends attached to a pair of well insulated flat springs of metal, mounted on the outer end of a radial arm, the latter fastened to a horizontal rod, coaxial with the armature. A well insulated piece of metal was fastened radially on the face of a disk attached to the armature shaft, and the two brushes set so that they were lightly touched by the radial strip at each revolution of the armature. A pointer attached to the horizontal shaft carrying the 
radial arm and contact springs, moved over a divided circle on the support of the arm, so that angular positions could be read. The contact device thus acted as an open circuit key, the closing of which, and the consequent eharging of the condenser, could only take place when the armature was in a definite position. The process of obtaining the curve of potentials through a revolution

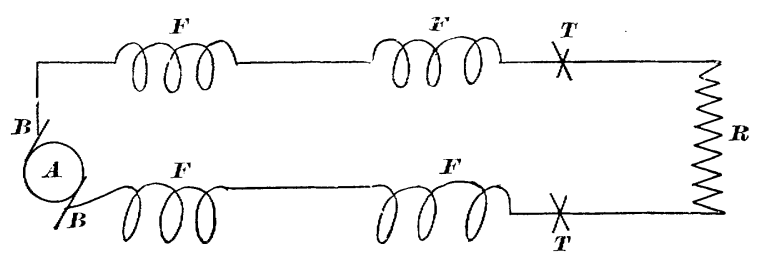

Fig. $\%$.

of the armature is now so familiar that further description is unnecessary.

In carrying out the examination of the machine, a non-inductive resistance of german silver wire was prepared to avoid complications from the action of the are lamp. When this was used as a load for the machine, the throws of the galvanometer changed at once from the erratic behavior observed at first, to the beautifully regular and uniform character now so familiar to all who have used the method under proper conditions.

Fig. 1 is a copy, to scale $\frac{2}{10}$, of the original curves of measurements made August 4. The inner circle gives the angular readings of the circle over which the pointer moved. Deflections of the galvanometer, on discharging the condenser through it, are plotted radially, at the angles at which they were obtained, the

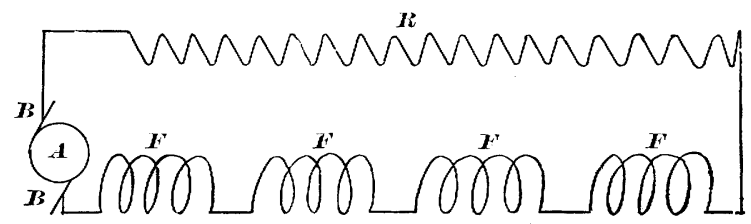

Fig. 3.

heavy circle being taken as zero. The scale is .2 volt per division. Curves $K$ and $L$ were obtained with the machine connected as in Fig. 2, in which $A$ is the armature, $B B$ the brushes, $F F$ the four field coils, $T T$ the terminals of the dynamo, and $R$ the noninductive resistance. The curve $K$ gives the deflections obtained when the condenser leads and wiper were joined at $T T$. It will 
be observed that the curve is symmetrical, giving eight maxima and eight minima per revolution. The minima are below zero, and explain the reversed deflections observed in the first work on the arc. The resistance $R$ being non-inductive, $K$ is also the curve of current strength, to a different scale, and shows that the machine was an alternating current machine, although the excess of positive area over negative shows an average positive current. Curve $L$ was taken with the machine in the same condition as before, but with the condenser leads attached to the brushes at $B B$. It gives the varying potential of the armature, as modified by the inductive reaction of the field, and shows the same symmetry, with less distortion. For curve $M$ the field coils were all thrown on one side of the armature and condenser leads attached to $B B$, as in Fig. 3 .

To ascertain the effect of an inductive external resistance on the terminal potentials of the machine normally connected, the connections used in obtaining curve $K$ were repeated, the only change made being to insert the six coils of the large Stevens electromagnet with the non-inductive resistance $R$, adjusting $R$ to get the same current strength used in getting curve $K$. The resulting curve showed the same characteristics as $K$, but much magnified, deflections ranging from -300 to +550 . Many other curves were taken, with the machine self-excited and separately excited, on various loads and on open circuit, but the results, though interesting, are not of sufficient importance now to occupy your time. The most interesting curves and results were presented as a joint paper by Prof. Morton and the writer, and read by Prof. Morton before the American Association for the Advancement of Science, at its Boston meeting, August 25-30, 1880. Immediately after that meeting the writer entered on his duties at the University of Missouri, and had no opportunity to resume the use of the method until his removal to Ohio in 1885 . It was used in that year by his students in an examination of the ThomsonHouston arc dynamo, substituting a Thomson portable electrometer, with Leyden jars to increase its capacity, for the condenser and galvanometer. Since then the method has been used in this laboratory on various apparatus, and in various ways, but it is needless to recount the details.

Our experience with the method leads us to prefer the Thomson portable electrometer and Leyden jars, to all other instruments 
for high potential curves. The electrometer is dead beat, is a zero instrument, and is easily and quickly set. As usually made, its constant is from two to three volts per division, and one can easily set to within that amount. The error resulting from an improper reading, say one division wrong, would be of course serious in reading low potentials, but these readings only occur on nearly straight parts of high potential curves, and might be entirely omitted without serious error.

Next to the portable electrometer, we prefer the Thomson electrostatic voltmeters. For low potential curves nothing has yet proven superior to the potentiometer method as used here, and described by the writer at the American Assuciation meeting at Washington last August. The potential difference to be measured

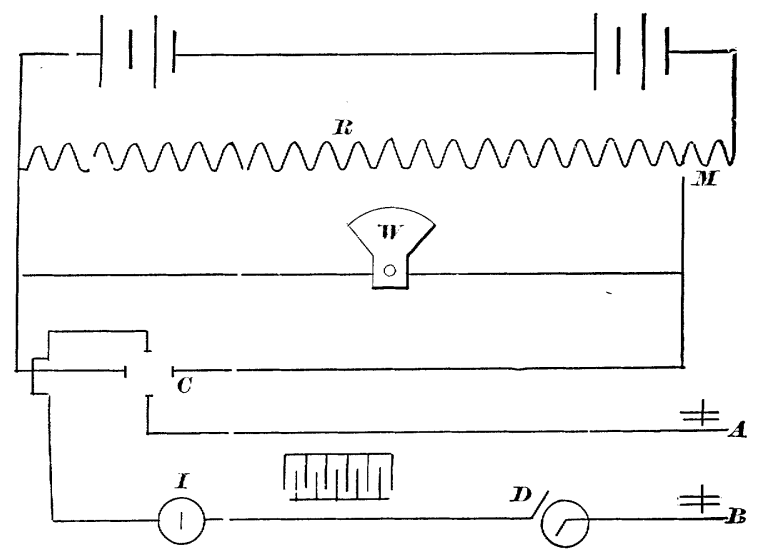

Fig。4.

is balanced against that produced by a battery in a resistance as in Fig. 4.

In the figure, $R$ is a resistance of some convenient form, with which contact may be made with a movable terminal $M$, or which may be varied between or beyond the terminals of the Weston voltmeter $W$. From these terminal wires leads through a commutator $C$, a sensitive galvanometer or telephone $I$, and the wiper $D$ to any points $A B$, whose potential curve is desired. The whole being in operation, and $C$ properly placed, $M$ or $R$ (or both) is adjusted until $I$ shows no current, when the potential difference existing at $A B$ is read off directly in volts on the voltmeter $W$. The use of the telephone is due to R. D. Mershon, a graduate of the university, who described the method in the Electrical World of August 29, 1891. 
Fig. 5 is a part of the potential curve recently taken from a Brush open coil motor, run as a dynamo on an inductive load. One-fourth of the complete curve is shown, and the parts not given are quite symmetrical with this. No "smoothing" is applied, but the observed points are joined by straight lines. The sharp angular form shown is due to the fact that readings were taken at intervals of five degrees, except between 25 degrees and 35 degrees, where readings were taken at each degree, to determine the character of the sharp variation between 30 degrees and 35 degrees. The change of 130 volts which occurs between 32 degrees and 33 degrees is unique and noteworthy, yet it is perfectly definite and characteristic, and has been repeatedly ob-

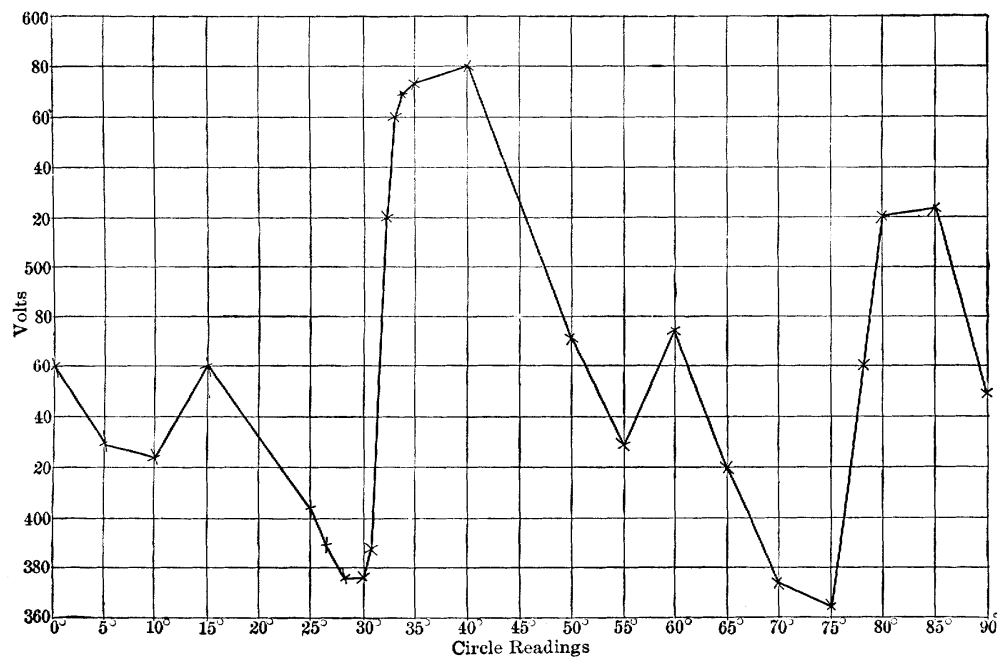

Fig. 5.

served under like conditions. The use of ammeters and voltmeters or galvanometers in power measurements on such machines must, as pointed out in the paper of 1880, lead to incorrect results.

In Mr. Thompson's paper referred to above, reference is made to Joubert's use of the method in 1881, and in the recent edition of Thompson's Dynamo-Electric Machinery, it is described as Joubert's method. In view of the work here described, and its presentation before the American Association in 1880, it seems proper to claim the method, which in the hands of Dr. Duncan, Professor Ryan and others, has led to such valuable results, as an American method. 


\section{Discussion.}

Dr. Nichols :-Mr. President, this is a subject in which I feel very much interest. It seems to me that we owe Prof. Thomas an expression of thanks for taking the trouble to revive the ancient history of this particular method which has grown to be of such importance. At the time when these measurements were made, they were so little appreciated as to have attracted no attention. The paper, as we know, was presented at the American Association for the Advancement of Science, and was regarded as a curions thing; and a dynamo itself at that time was regarded as hardly worthy of study in this country. So far as I know the history of this matter, the next place where this method crops out was in 1884, in Philadelphia, where it began to be seriously considered, and where it was put into practice, or at least considered one of the ways in which dynamos were to be studied. And certainly from that time on, in various laboratories. it was the method for practice work on dynamos, year after year. Prof. Jackson himself, who is with us to-day from Madison, doubtless can remember a great number of curves which he took by this same method in the laboratories of Cornell University in those days. The application of it to alternating current curves shonld donbtless be credited to Joubert. The graphic data accompanying the paper. I think is extremely interesting in its bearing upon the history of this important method, and is well worthy of a place upon our records.

[A vote of thanks was tendered to Professor Thomas for his efforts in collecting these facts for the benefit of the Institute, and upon its invitation.]

Mr. Chas. F. Scott :-Mr. Chairman, I may make a statement with regard to the use of the telephone method referred to by Prof. Thomas. Mr. Mershon, to whom that method is due, is now with the Westinghouse Electric Company, and has used the method in the laboratory work of the company in taking curves of electromotive force and current from alternating machines. The telephone is an extremely delicate instrument, and as we all know, is very liable to give undue prominence to sounds that are not wanted. In using the telephone we found that varions sounds from the dynamo engine room could be distinctly heard, but the click of the contact is peculiar and can easily bo detected and the sliding resistance can easily be adjusted so as to eliminate the sound of the contact, showing that the proper adjustment is made although other sounds may still be heard. Repeated settings can be made with very great accuracy. On one occasion a gentleman who was not accustomed to making electrical readings was invited to make a number of settings. I took the readings on a Weston voltmeter, and they ran something like this: $76.9,76.8,76.9,76.9$, and so on. showing that the method is susceptible of very great accuracy. It is a practical method, and can be readily and rapidly applied.

Professor J JCKson:-Mr. President, I think in the fall of 
1885 I first learned of a similar method when I went to the laboratory at Cornell University. We then had several machines arranged for very careful examination in this manner: One was the old Ball dynamo, and I remember going through that machine with a great deal of pleasure a number of times. I have no doubt from the results that have come from Cornell since those days, that they have used and explained the methods many times. The method is undoubtedly one of the most satisfactory that can be used for studying the action of a dynamo.

The portable instrument that Dr. Nichols spoke of yesterday for taking sornewhat similar curves, I am very much interested in, and trust that the subject will be more fully developed in the litboratory at Cornell. Such a portable instrument must be the natural outcome of the careful study that is now being made of the magnetic fields of dynamos, and if it can be put into commercial shape it will be practically invaluable to dynamo manufacturers.

Professor Carhart :-Mr. President, it would be well to have a little corroborative testimony of what Professor Thomas has stated. It does not go back to 1880 , but I remember very distinctly in 1884, in Philadelphia, Professor Thomas and I were examining different machines, and the reference to this Ball machine revives it very strongly. We came in the vicinity of that, and I recollect Professor Thomas expressed a very ardent desire to explore the region around the armature of that machine, and that accounts for his interest in the subject, because he liad already been practicing this method. 